\title{
Short-term mechanical support and pharmacotherapy, a new strategy in cardiogenic shock?
}

\author{
C. C. S. Tseng • S. A. J. Chamuleau • N. De Jonge • \\ F. Z. Ramjankhan
}

Published online: 19 February 2014

(C) The Author(s) 2014. This article is published with open access at Springerlink.com

Editorial comment on Preventing LVAD implantation by early short-term mechanical support and prolonged inodilator therapy: a case series with acute refractory cardiogenic shock treated with veno-arterial ECMO and optimised medical strategy'

J.J. Brugts, O. Manintveld, A. Constantinescu, D. Donker, R. van Thiel, K. Nieman, L. Jewbali, F. Zijlstra, K. Caliskan

In this issue of the Netherlands Heart Journal, Brugts et al. describe a series of cases with acute severe refractory cardiogenic shock [1]. All three patients had no relevant cardiac history and were initially referred for durable left ventricular assist device (LVAD) implantation and/or heart transplantation (HTx). Dilated cardiomyopathy was diagnosed in two patients (one with an unknown cause, one due to alcohol/ toxicity), while parvo B10 viral myocarditis was confirmed by biopsy in the other patient. Veno-arterial extracorporal life support (VA-ECLS) was started because a high dose of positive inotropes and intra-aortic balloon pump (IABP) were insufficient. Low-dose beta blocker and ACE inhibition were initiated early and titrated in combination with phosphodiesterase inhibition (enoximone). In all three cases cardiac function recovered and the patients were successfully weaned from VA-ECLS without any signs of relapse in up to 3.5 years of follow-up.

The authors conclude that the combination of extracorporeal membrane oxygenation (ECMO) and early introduction of heart failure medication under the umbrella of

C. C. S. Tseng $\cdot$ S. A. J. Chamuleau $\cdot$ N. De Jonge Department of Cardiology, UMC Utrecht, Heidelberglaan 100, 3584 CX Utrecht, the Netherlands

F. Z. Ramjankhan $(\bowtie)$

Department of Cardio-Thoracic Surgery, UMC Utrecht, Heidelberglaan 100, 3584 CX Utrecht, the Netherlands e-mail: f.ramjankhan@umcutrecht.nl phosphodiesterase inhibition provided momentum to survive and prevent LVAD implantation.

The introduction of extracorporal life support in the 1970s has defined the standard of care in so-called 'crash and burn' (INTERMACS 1) patients [2]. The clinical management of this patient category is still hampered by the high mortality rate but also by the lack of accurate guidelines to confirm the appropriate patients and timing for mechanical circulatory support [3].

The rise of durable LVADs has significantly improved survival in end-stage heart failure and has provided a successful bridge to transplantation [4]. However, results of durable LVADs as bridge to recovery are poor, with maximal sustained recovery rates of $20.5 \%$ recorded by Birks in a large cohort of 92 patients with an aggressive supporting pharmacological regimen $[5,6]$. Though infrequent, cardiac recovery is primarily seen in non-ischaemic cardiomyopathy with divided aetiology between myocarditis, peripartum cardiomyopathy and idiopathic, potentially reversible causes of heart failure [5-7].

Analysis on survival after implantation of a durable LVAD in different INTERMACS categories revealed dramatically high mortality rates in INTERMACS profiles 1 and 2, compared with less critically ill patients [8]. This finding gave rise to the current applied strategy of shortterm mechanical circulatory support in 'crash and burn' patients [2]. Especially in potentially reversible causes of cardiogenic shock, temporary ECLS can be sufficient. When recovery does not meet explantation criteria a longterm device and/or heart transplantation is still indicated. Although the strategy of preventing LVAD implantation by early short-term mechanical support and prolonged inodilator therapy is described in the present case series as a novel approach, clinicians worldwide are already initially treating INTERMACS profile 1 patients with short-term mechanical support to prevent mortality. 
To promote reversal of heart failure, different combinations of pharmacological strategies have been investigated. For example, sustained recovery was seen in the majority of a small group of patients with acute and severe non-ischaemic cardiomyopathy without active myocarditis treated with a strict pharmacological treatment consisting of the $\beta 2$-agonist clenbuterol [9]. From the investigated combination of heart failure medication with enoximone, no conclusion can be drawn. Widely, the benefit of beta blockers in unstable severe heart failure is lacking evidence, due to routine exclusions in studies, and one should be extremely cautious in case of right ventricular failure [3, 10].

A recent retrospective study on early heart failure pharmacotherapy in ongoing cardiogenic shock compared patients who did and did not receive heart failure therapy within $24 \mathrm{~h}$ of admission. In comparison with no therapy, administration of $\beta$-blocker was significantly associated with an increased 30-day mortality and longer median duration of shock [11].

Rather than preventing the pathway of long-term LVAD support, the reported cases elegantly describe recovery of heart failure with state of the art treatment with ECLS in potentially reversible causes of cardiogenic shock. The additive value of the pharmacological regimen cannot be concluded from this series without a control group. Controlled studies are necessary to examine the value (or harm) of early introduction of heart failure medication.

\section{Funding None.}

\section{Conflict of interest None declared.}

Open Access This article is distributed under the terms of the Creative Commons Attribution License which permits any use, distribution, and reproduction in any medium, provided the original author(s) and the source are credited.

\section{References}

1. Brugts JJ, Manintveld O, Constantinescu A, et al. Preventing LVAD implantation by early short-term mechanical support and prolonged inodilator therapy: a case series with acute refractory cardiogenic shock treated with veno-arterial extracorporeal membrane oxygenation and optimised medical strategy. Neth Heart J. 2014. doi:10.1007/ s12471-013-0509-5.

2. Samuels LE, Holmes EC, Hagan K, et al. Cardiogenic shock: collaboration between cardiac surgery and cardiology subspecialties to bridge to recovery. Ann Thorac Surg. 2007;83(5):1863-4.

3. Remme WJ, Swedberg K. Guidelines for the diagnosis and treatment of chronic heart failure. Eur Heart J. 2001;22(17):1527-60.

4. Rose E, Gelijns CMA, et al. (REMATCH study group). Long-term use of a left ventricular assist device for end-stage heart failure. $\mathrm{N}$ Engl J Med. 2001;345(20):1435-43.

5. Mancini DM, Beniaminovitz A, Levin $\mathrm{H}$, et al. Low incidence of myocardial recovery after left ventricular assist device implantation in patients with chronic heart failure. Circulation. 1998;98(22):23839.

6. Birks EJ, Khaghani A, George RS, et al. Long-term outcomes of patients bridged to recovery versus patients bridged to transplantation. J Thorac Cardiovasc Surg. 2012;144(1):190-6. The American Association for Thoracic Surgery.

7. Maybaum S, Mancini D, Xydas S, et al. Cardiac improvement during mechanical circulatory support: a prospective multicenter study of the LVAD Working Group. Circulation. 2007;115(19):2497-505.

8. Alba AC, Rao V, Ivanov J, et al. Usefulness of the INTERMACS scale to predict outcomes after mechanical assist device implantation. J Heart Lung Transplant. 2009;28(8):827-33.

9. Birks EJ, Tansley PD, Hardy J, et al. Left ventricular assist device and drug therapy for the reversal of heart failure. N Engl J Med. 2006;355(18):1873-84.

10. Meuwese CL, Kirkels JH, de Jonge N, et al. Beta-blocker therapy in unstable severe heart failure, evidence or experience? Neth Heart J. 2013;21(1):3-5.

11. Van Diepen S, Reynolds HR, Stebbins A, et al. Incidence and outcomes associated with early heart failure pharmacotherapy in patients with ongoing cardiogenic shock. Crit Care Med. 2014;42(2):281-8. 